\title{
Sinophobic Epidemics in America: Historical Discontinuity in Disease-related Yellow Peril Imaginaries of the Past and Present
}

\author{
Dennis Zhang ${ }^{1}$ (D)
}

Accepted: 30 December 2020 / Published online: 22 February 2021

(c) The Author(s), under exclusive licence to Springer Science+Business Media, LLC part of Springer Nature 2021

\begin{abstract}
Modern scholarship has drawn hasty and numerous parallels between the Yellow Peril discourses of the 19th- and 20th-century plagues and the recent racialization of infectious disease in the 21 st-century. While highlighting these similarities is politically useful against Sinophobic epidemic narratives, Michel Foucault argues that truly understanding the past's continuity in the present requires a more rigorous genealogical approach. Employing this premise in a comparative analysis, this work demonstrates a critical discontinuity in the epidemic imaginary that framed the Chinese as pathogenic. Consequently, those seeking to prevent future disease racialization must understand modern Sinophobia as fundamentally distinct from that of the past.
\end{abstract}

Keywords Yellow peril · Disease racialization · Sinophobia - Epidemic imaginary · COVID-19

\section{Introduction}

Modern scholars have drawn many parallels between the Yellow Peril intertwined narratives of the 19th- and 20th-century plagues and the recent 21st-century racialization of the 2002-2004 severe acute respiratory syndrome (SARS) outbreak as well as the ongoing coronavirus disease 2019 (COVID-19) pandemic. The resurfacing of Sinophobic and anti-Asian sentiments has renewed scholarly attention to century-old historical precedents linking the Chinese, Chinese Americans, and others of Asian descent who have been mistakenly imagined as "Chinese" (hence their interchangeable use throughout this work) to infectious diseases (Tessler, Choi, and Kao 2020; Kim and Shah 2020). Although these parallels may serve as powerful political tools in the modern crusade against Sinophobic renderings of infectious disease threat, Christos Lynteris (2018b, 49) has cautioned against the fallacy that Michel Foucault (1977) famously denounced as the "passion for origins," in which drawing these connections appears analytically luring for their usefulness in times

Dennis Zhang

dz2404@columbia.edu

1 Columbia University, New York, NY 10027, USA 
of danger. Invoking Friedrich Nietzsche's notion of genealogy, Foucault notes that "this search is directed to 'that which was already there,' the image of a primordial truth fully adequate to its nature, and it necessitates the removal of every mask to ultimately disclose the original identity" (142). Simply put, engaging in the genealogical method requires that we abandon our searches for ideal origins and the preconceived authority of "truths," which then enables us to critically deconstruct these truths and truly understand how "the past actively exists in the present" (146). Foucault's genealogical approach, the methodological premise of this work on past and present Sinophobia during times of epidemic, informs a rigorous examination that challenges the assumed uniformity (across otherwise distinct phenomena) that often emerges from the observation of easily apparent similarities.

Lynteris (2018b) has laid the foundation for this work in his own investigation of the American Sinophobic discourses and sociocultural perspectives of the 19th-/20th-century past and 21st-century present that associated the Chinese with the threat of infectious disease. For the sake of concision and consistency, I will refer to the former period as the "classical period" and the latter as the "contemporary period" throughout my own work. While Lynteris aptly recognizes the common emphasis across both periods in identifying China and the Chinese, respectively, as "sources" and "spreaders" of disease, he applies Foucault's genealogical premise in a comparative anthropological and historical analysis that exposes a vital discontinuity in the political ontology of the Sinophobic social imaginations that characterized each period. In short, he demonstrates that classical fear of the Chinese as sources and carriers of diseases were due to China's perception as a land of "degeneration" and "decay," while contemporary fear instead predicated on China as a land of "emergence" (36). By examining classical epidemic imaginaries that relied upon notions that infectious diseases were derived from the processes of decay and degeneration, Lynteris demonstrates how these notions were central to the perceived political and social condition of the late Qing Empire. He then sharply juxtaposes this ontology with that of contemporary epidemic imaginaries that were fueled by fears of unpredictable disease emergence in the secretive land of China, which had arisen by then as a postsocialist economic and political power on the world stage (49). Notably, Lynteris' comparative analysis relies upon the image of the "South Chinese wet market," which functioned as a "symbolic condenser of narratives" regarding the Western understanding of China as a source of disease across both the classical and contemporary periods (45-46). In examining the wet market, Lynteris specifically fixes his analytical gaze on the imagined mode of disease generation, rather than the imagined mode of disease transmission that usually comes under sociological scrutiny. While the wet market was understood in classical discourses as places of "filth, putrefaction, and noxious smells and effluvia" that had the potential to spawn ancient diseases (like the bubonic plague), they were instead exceptionalized throughout the contemporary period as foci where pragmatically novel diseases emerged.

The aim of this work is to serve as a broader proof of concept for a fundamentally distinct modern Sinophobia as proposed by Lynteris (2018b). While it simultaneously takes into consideration the role of China's perceived transformation from a land and culture of decay and degeneration to one of emergence through its intentional division of classical and contemporary periods, this analysis differs from Lynteris' work in regards to its focus as well as its scope. While Lynteris' work primarily focused on the supposed mode of disease generation (i.e. decay/degeneration and emergence), the major novel contributions of this analysis are (1) its examination of the imagination surrounding Chinese disease response and how this perception shaped broader Sinophobic epidemic narratives and (2) its timely expansion of scope to consider further the epidemic imaginary surrounding the ongoing COVID-19 pandemic. In adopting Foucault's genealogical framework as well 
as employing a comparative analysis approach similar to that of Lynteris, I will point out a crucial discontinuity across classical and contemporary imagination of the Chinese in regards to their perceived pathogenicity due to divergent responses to disease. Although the classical "pathologization" of Chinese immigrants was, in part, driven by an imagined cultural response to infectious disease that ran contrary to Western scientific modernity, contemporary epidemic narratives instead predicated on novel fears of a collective Chinese embrace (and even exploitation) of this very modernity.

\section{Sinophobia in the classical period: 19th- and 20th-century Yellow Peril}

During the early years of Sino-American trade, Chinese civilization was generally held in high esteem, yet the current consensus among American historians is that the late 1840s marked the beginning of increasingly negative attitudes towards the Chinese (Miller 1969, 16). Scholars generally attribute this change in viewpoint to the increase in Chinese immigration at the time (Lee 1960, 354). From the late 19th- to early 20th-century, incoming Chinese immigrants, mostly young men and laborers, often left their overcrowded and wartorn homes for the lure of gold in cities like San Francisco, California. In spite of the initial welcome of newspapers like San Francisco's Daily Alta California, nativist cries soon emerged as Chinese immigrants competed for jobs traditionally held by white Americans, resulting in violence, verbal abuse, and demands for heavy taxes on these new eager workers (Takaki 1998, 68-69).

Newly emergent Sinophobic beliefs, characterized by the racist color metaphor of "Yellow Peril," were rooted in diverse, multi-layered fears that ranged from the foreignness of Chinese bodies and cultures to China's large population and potential for imperialism (Lee 1999; Fong 2002, 189). According to Ronald Takaki (1998) in Strangers from a Different Shore, the subsequent degradation of the Chinese into a "subservient caste of laborers" was principally fueled by the prevailing sense among late 19th-century white Americans that "America [was] a racially homogeneous [white] society," meaning that Chinese immigrants were understood as a threat to the white national identity (82). Moreover, as the national debate over immigration continued, Yellow Peril discourse would later play a key role in justifying Asian exclusion in immigration policies, such as the 1882 Chinese Exclusion Act; the American colonization of Hawaii, Guam, Samoa, and the Philippines; and the nation's maritime expansion beyond the West Coast towards the Asia-Pacific region (Lee 1999; Okihiro 1994). According to Joan B. Trauner (1978), by the 1870s, the admiration of the Chinese that had marked the 1840s transformed into a multi-faceted Yellow Peril argument that advanced economic, cultural, assimilationist, racial, biological, and medical claims against the Chinese.

The medical framing, in particular, of Yellow Peril enabled American scapegoating of the Chinese during times of epidemic. While the ensuing discourse was fragmented and multi-layered, it had a common emphasis on identifying China and the Chinese as sources and spreaders of disease (Lynteris 2018b). During the 19th- and 20th-century epidemics of smallpox and bubonic plague, American public health officials and Western media did not hesitate to blame disease outbreaks on the Chinese. San Francisco, the hub of Chinese immigration during the California Gold Rush, is a fitting case study to observe this broader trend of racial discrimination thanks to the particularly sizable Chinese immigrant population, as well as the resultingly high levels of Sinophobic tension. 
When the 1875-1876 San Francisco smallpox epidemic struck in waves, the city Health Officer immediately suspected that its proliferation was largely due to the Chinese population and ordered the fumigation of all houses in the city's Chinatown to no avail as smallpox continued to rage on. Unable to account for the hundreds of white lives that continued to be lost from other areas of the city, he resorted to publicly denouncing the Chinese themselves as "lying" and "treacherous" ("San Francisco Municipal Reports" 1887, 397). Popular local newspapers, like the conservative, anti-Chinese San Francisco Chronicle, also promulgated notions that the Chinese were unequivocally to blame for bringing the disease and spreading it (San Francisco Chronicle 1876). It is interesting, however, to note here that Donald R. Hopkins (1983) points out that the second wave of smallpox was, in fact, first introduced by European and American immigrants coming from the smallpoxstricken East and Midwest United States.

In terms of framing the Chinese as medical scapegoats, the ensuing bubonic plague epidemic that struck San Francisco in 1900 was no different. Upon the suspicious death of a Chinese resident, the city mayor promptly quarantined all of the Chinatown's residents and ordered an investigation into those suspected of contact with the sick (McClain 1988). While the Chinese were baffled by the decision to close off the entire district, an intimidating display of force by health officials and the police, Chinatown representatives threatened to file a legal injunction before the quarantine was lifted (Risse 2012, 113-116). However, a repeated cycle of quarantine, deportation, and fumigation threats and Chinese resistance (as I will discuss later) would soon ensue as other bubonic plague cases were discovered. Occasionally, Chinatown representatives and the San Francisco Health Board were able to challenge each other in court, where, in one case, the health board's quarantine measures were deemed illegal while its cleaning and fumigation efforts were upheld (139). Regardless of legal rulings and occasional vindications of the Chinese, however, popular Sinophobic newspapers like the San Francisco Call continued to falsely racialize the bubonic plague as an "Asiatic pestilence" and suggest that the physical, and perhaps moral, purging of the Chinatown was long overdue, regardless of the plague itself (San Francisco Call 1900).

Given the clear ramifications of medically-framed Yellow Peril discourses, it is essential to understand the key aspects of the discourses that enabled the association of the Chinese with infectious disease. In general, Lynteris $(2018 b, 37)$ has categorized current scholarship on classical disease-related Yellow Peril discourse into four main imaginations revolving around "China," "Chinese urban spaces," "Chinese bodies," and "Chinese culture." Here, I will briefly discuss them to frame the scholarship that surrounds my own extended analysis into the imagination surrounding Chinese culture through the lens of perceived Chinese disease response. It is further important to note here that the following discussion of the Yellow Peril medical argument centers around 19th- and 20th-century outbreaks, such as smallpox and bubonic plague, because of heightened levels of Sinophobia and Chinese-disease association, particularly in America, that arose during these classical era infectious disease scares.

The first imagination was of China as the original source of disease. In particular, the 19th-century return of bubonic plague was imagined to have first arose from China. In March 1894, the city of Hong Kong was home to the first known bubonic plague outbreak to capture global attention. Lynteris (2018b) writes that this outbreak not only framed Hong Kong as the epidemiological origin of the subsequent global pandemic that would take upwards of twelve million lives across major urban centers such as like San Francisco, Sydney, Glasgow, and Harbin, but also crafted a "mythic [pandemic] prehistory" that associated bubonic plague with the decline of the Qing Empire (37). Fueled by international 
press coverage, panic captured the public imagination, which dreadfully envisioned a potential return of the apocalyptic "Black Death" that had once ravaged Europe (38). Indeed, the imagination of China as the origin of plague was critical towards driving public fear and racializing it as a Chinese disease.

From imagining China as the source of disease, the next key imagination was of Chinese urban spaces as the grounds where diseases would breed and proliferate. The specific medical argument that advanced this imagination was that "the Chinese, ignoring all laws of hygiene and sanitation, bred and disseminated disease, thereby endangering the welfare of the state and of the nation" (Trauner 1978). Indeed, filth consciousness varies among societies, and Chinese immigrants originated from a largely rural, pre-industrial society, in which crowded and dirty conditions were common (Risse 2012, 68-69). In America, however, their visibly unsanitary and highly odorous Chinatown neighborhoods and urban spaces contrasted Western medical emphasis on good hygienic practices through early ideas that "dirt" bred disease as well as the later advent of modern bacteriology (Miller 1969, 194). Unaware that environmental conditions could breed infectious disease, Chinatown residents reportedly failed to remove garbage and often used human waste as fertilizer (Risse 2012, 68). To the general public outside of Chinatown, these unhygienic neighborhoods were seen as contaminated spaces of contagion and breeding grounds for disease that threatened to infect the rest of the urban body. Moreover, as representative visual symbols of Chinese civilization itself, these neighborhoods were further interpreted as evidence of Chinese socioeconomic, cultural, and even moral decay.

The third imagination was of Chinese bodies as special vectors of disease transmission. After framing Chinese spaces as breeding grounds for disease, Chinese immigrant bodies were imagined as especially pathogenic because of an array of race- and class-related fears. In general, the Chinese were seen as an Oriental race of "coolies," meaning that they were an inherently inferior race especially susceptible to disease. For instance, under early principles of miasma theory, where disease is believed to be caused by foul odors, these odors were suspected of engulfing entire American neighborhoods and cities, meaning that all residents faced more or less equal environmental risks. This, in turn, corroborated notions that higher prevalence of disease among Chinese residents who lived in unsanitary Chinatowns were because of inherent racial susceptibility rather than environmental factors (Risse 2012, 67).

Finally, the fourth imagination was of Chinese culture itself as conducive to disease. In Larissa N. Heinrich's $(2008,70)$ examination of Lam Qua's pathological portraits featuring Chinese patients deformed by tumors and fibromata, he discusses the pathologization of Chinese cultural identity as based on perceived Chinese features, such as insensibility to pain, inadequate traditional medicines, cultural inability to perform autopsies, and general superstition. This dehumanizing visual trope, representative of the greater public imagination surrounding the Chinese and their relationship to disease, suggests that the seemingly antiquated, ancestor-focused, and even fatalistic culture of the Chinese, rather than solely their hygienic and/or medical practices, was overall conducive of disease for its cultural stagnancy.

This fourth imagination surrounding Chinese culture is one that I will further analyze in the next section. Specifically, I will examine the imagined Chinese response to disease during the classical period with an emphasis, in particular, on the bubonic plague epidemic. In doing so, I will link these behaviors to the perception of Chinese culture, again, as one of stagnation and, more specifically, one of rejecting scientific modernity. In the larger scheme of my argument for a discontinuity between classical and contemporary epidemic imaginaries, my emphasis on imagined Chinese disease response will provide a 
crucial basis of comparison for the relationship between Chinese culture and modernity that defined each era.

\section{The classical imagination of Chinese response to infectious disease}

This section serves as an examination of the Chinese response to disease and Western preventative measures before and during the bubonic plague, as well as the public perception of that response (in regards to framing the broader Sinophobic epidemic narrative). As noted earlier, San Francisco, a particularly Sinophobic region, is a powerful case study for examining the dynamics before and during infectious disease scares. In his highly detailed account of the 1900 bubonic plague outbreak in San Francisco, Guenter B. Risse (2012) provides significant insight into individual actions, historical events, media coverage, and cultural dynamics that enabled the racialization of disease and discrimination against the Chinese.

Throughout the classical period, the Chinese interpreted disease through the interlinked traditional lenses of religion, astronomy, and superstition. During the late Qing dynasty, Chinese immigrants to California brought with them the popular, intricate system of religious beliefs and practices that had been constructed over millennia. Risse writes:

The Chinese universe was conceived as a three-layered space with an upper yang world of heaven (tian), populated by gods and ancestors, a crowded middle earthly domain (yang jian) where the living and gods interacted, and an underworld (yin jian) populated by ghosts and devils. Each region was hierarchically structured and considered a mirror image of traditional Chinese society, organized into an imperial court and state bureaucracies with magistrates, secretaries, and attendants. Instead of a centralized religious dogma, fluid relationships between these spheres generated a complicated set of beliefs and rites. In China, "religion" remained a complex web representing philosophical schools, or Three Teachings (san jiao), namely Confucianism, Daoism, and Buddhism. All had been intimately entwined since the Song dynasty (960-1279) and pervaded all aspects of Chinese life, including imperial ideology and rule. (40-41).

As a result of this relatively homogenous lens of the cosmos, the Chinese collectively understood natural phenomena and daily happenings as consequences of the constant struggle between yang forces (benign gods and demigods living in heaven) and yin forces (malicious ghosts and demons of the underworld). In practice, to defend themselves from evil spirits, Chinatown residents performed local rituals and worshipped a variety of saints and divine beings. For instance, during times of disease outbreaks, which were interpreted as inevitable due to the will of deities, residents tossed flaming papers into sandpits and then interpreted charred shapes as divine messages and prescriptions. In addition, they would commonly wear protective amulets, paste prayer papers on their front doors, burn incense, conduct exorcisms, and even use magic spells to ward off evil and cultivate vitality. In spite of these culturally-ingrained self-help practices, however, fatalistic submission to divine will was common among the Chinese (43-45).

In cases where Chinatown residents did occasionally seek external help, the typical next option would be to consult local Chinese medical practitioners. These practitioners often did not possess legal state licenses, lacked educational requirements because of lenient Chinese medical education at the time, and relied on memory and intuition rather than 
central medical texts. Moreover, Chinese medicine never truly obtained a unified theory of practice and instead emphasized a holistic view of disease. Altogether, this reality of Chinese medical beliefs, practice, and theory meant that individual biological phenomena driving common infectious diseases could not be understood in isolation by either Chinese doctors or everyday Chinatown residents (46-48).

The Eastern medical paradigm stood in sharp contrast to that of America throughout the classical period. Informed by Britain's sanitary model and the widely accepted doctrine of miasma theory, the 1849 reappearance of cholera drove lasting public health emphasis on sanitation as disease prevention (67). By the 1890s, the birth of bacteriological principles like germ theory, which argued that infectious disease phenomena were caused by invisible microscopic agents that invaded the human body, multiplied, and finally harmed the host, further backed a growing Western obsession with hygiene and sanitary action (69). In San Francisco, the permanent health board (established during the earlier cholera outbreak) implored sanitarians to monitor the city's public health and implement regulations with an emphasis on unsanitary garbage-filled streets and neighborhoods where the genesis of disease would be most probable (70-71).

Although unhygienic conditions prevailed across several neighborhoods in San Francisco, sanitarians understood the city's Chinatown to be an especially filthy breeding ground of disease. While Sinophobic beliefs partially accounted for this discriminatory attention, it was not entirely unwarranted. Because of traditional beliefs in astronomical patterns, seasonal changes, and superstition as reliable predictors of disease, Chinese immigrants were largely indifferent to notions of filth and direct contagion from their increasingly unhygienic urban environments (68). As noted earlier, these often poor immigrants had also arrived from a pre-industrial society where odors, air pollution, and overcrowding were considered typical, and public health action merely involved the proper burial of unattended corpses (66-68). Furthermore, San Francisco's sheer lack of Chinese women who traditionally held necessary roles in housecleaning and a faulty city garbage collection system ensured that personal and domestic hygiene in the impoverished Chinatown worsened as significant amounts of waste simultaneously accumulated (71-72).

This general Chinese indifference to unhygienic conditions, however, did not remain unchallenged by the San Franciscan public during the classical period. While the city initially disallowed the creation of a Western hospital in Chinatown throughout the 1860s, the following decade witnessed local newspapers urging leading Chinese merchants to follow the examples of the modernizing cities of Hong Kong and Macao in establishing a hospital of their own (52). In another key effort, the San Francisco Health Board sent inspectors to houses in Chinatown to replace outdated plumbing systems (72). By the early 1900s, Chinese leaders, too, attempted to modernize China and Chinatown with Western ideas and medical practices. One such institution was the Tung Was Dispensary, which opened on March 3, 1900. It was a small community institution led mostly by well-known Chinese practitioners meant to treat ambulatory patients and occasional emergencies (53-54). Additionally, these leaders reluctantly endorsed "crusades" against filth, which were Western sanitary efforts to instill better hygienic practices and conditions in Chinatown (74).

In general, however, these efforts proved counterproductive for the everyday Chinese residents of San Francisco's Chinatown. Most of the Chinese already distrusted Western healthcare facilities due to the view that foreigners were providing polluting "death bed" care. Furthermore, when plans were made to circumnavigate this distrust of the West during the 1888 smallpox epidemic by creating a Chinese isolation facility, these efforts, perhaps out of bad luck, logistically failed (52). Not to mention, the health board's efforts to update plumbing systems were met with stubborn opposition as some Chinese insisted 
on retaining cesspools as a gesture of defiance. Chinese tenants also found the American emphasis on plumbing exceedingly difficult to grasp and fearing rent increases and intrusions of their homes, rejected domestic improvements by destroying new drainpipes upon installation (72). The Tung Was Dispensary and the city's filth crusades were similarly met with widespread indifference, unable to substantially influence Chinese cultural beliefs and sanitization practices (74). These defiant attitudes were universal across classical period Chinese responses to public health efforts, and the 1900 bubonic plague outbreak would prove no different.

In the late eighteenth century, Central Asia's natural rodent reservoirs gave rise to the third pandemic of bubonic plague, a frightful and lethal disease that vividly captured Western historical memory and, just a few centuries before, had devastated millions throughout Europe. As the result of population growth, urbanization, and trade, it spread through China and made its way around the world. In 1900, San Francisco would witness its first suspected case: the suspicious death of a Chinese man. The outbreak that soon followed serves as a compelling historical exemplification of the stark contrast between Chinese and Western disease interpretations and public health responses.

Aligned with their traditional paradigm of interpreting disease, the Chinese saw the bubonic plague, the "rat epidemic," as a destined convergence of divine factors, such as gods, stars, seasonal changes, dangerous food, poisonous qi, and even spirits (76-77). Given their beliefs in yin-yang harmony, they sought to restore balance between the good and evil. Harnessing the cacophony of gongs, bells, and fireworks, they carried out parades and processions in order to deter evil pestilences (115). Alternatively, the West interpreted the bubonic plague through the seamless integration of the traditional miasmatic paradigm with the recently developed bacteriological paradigm. While the plague was seen as a soil disease (caused by contact with the unsanitary) through a miasmatic lens, the only significant shift in understanding through later bacteriological principles was that the exact mechanism of pathogenesis was attributed to a specific microbe that resided in unhygienic spaces. As such, the Chinese were similarly targeted, due to their dirty, bare earthen house floors and unhygienic urban spaces. For instance, traditional public health measures, like prompt quarantine, case detection, segregation of those in contact with the ill (sometimes through deportation), and disinfection (occasionally through the complete fumigation of houses), remained scientifically supported by bacteriology (77).

Throughout the plague outbreak, a cyclic dance between Western public health measures and Chinese rejection ensued. Since the early smallpox epidemics, sanitarians, backed by policemen who had longed to aggressively remove Chinese residents (83), had haunted the Chinese with orders of forceful deportations and/or herding of the infected into municipal isolation facilities. While the Chinese, concerned about their familial and collective honor (116), had already been customarily hiding plague cases, the constant specter of such aggressive measures resulted in an increasingly widespread effort of passive resistance such as refusal to cooperate which only further irritated city health inspectors and epidemiologists (65). Eventually, the San Francisco Health Board ordered house-to-house searches of plague cases and more cleaning/fumigation efforts throughout Chinatown. Highly protective of their privacy and concerned that the entire district could be destroyed, many of the Chinese, yet again, rejected these efforts by choosing to flee the city instead of collaborating with officials (117). In addition, an anti-plague immunization effort was also made by Western medical leaders who sought to inoculate all Chinatown residents with the Haffkine prophylactic recently developed in India (115). Specifically, the vaccine program sought to counter Chinese resistance by banning those who failed to receive the vaccine from leaving the city. However, this plan, like many similar programs before and after, was 
viewed by the Chinese with intense skepticism as a violation of personal health and privacy akin to opening one's home door to thieves (121). Moreover, while Chinatown leaders urged the greater Chinese public to stay patient as they re-negotiated the vaccine program with San Franciscan officials, many ordinary Chinatown residents voiced their willingness to be deported back to their homeland rather than surrender to the Haffkine vaccine. The result was yet another failed negotiation as Chinatown leaders instead sought federal protection from local authorities (124-28). Altogether, as San Franciscan officials became exceedingly frustrated with the Chinese lack of cooperation, their public health measures became more intrusive. Extensive cleaning campaigns, fumigations of houses, and quarantines were constant threats, and public tension exacerbated as newspapers repeatedly demanded that all of the Chinese be removed immediately (132-212).

The broader impact of the Chinese residents' responses to disease and public health measures was a Western imagination of their culture as a degenerate, stagnant rejection of modernity. Alongside their perpetual resistance to intrusive Western public health measures, Chinese refusal to cleanse filth and foul odors, visual and olfactory indications of human values, was equated with a fundamental embrace of chaos and barbarism (67). Health officials utilized a dramatic narrative style to frame Chinatown as an unrelenting health threat and thereby a "great reservoir of moral, social, and physical evil," going so far as to describe an alley in Chinatown as "defying all civilization" (71-74). This apparent dogged rejection of the fruits of civilized American life continued to drive public prejudices while simultaneously justifying public health measures that, upon their rejection by the Chinese, further reinforced these very same Sinophobic beliefs. Perhaps best summed up by Stuart Creighton Miller (1969), the afflictions of the Chinese were perceived to be nothing more than the deserved result of "thousands of years of resistance to the efforts of all modern medicine" (163). Cultural rejection of scientific modernity and embrace of stagnancy was a defining aspect of this classical imagination of the Chinese and one of the foundational bases upon which they were imagined to be pathogenic. In a sense, it was this very culture of rejecting modernity that, according to the American public, appeared to bring about their maladies.

\section{Sinophobia in the contemporary period: 21 st-century racialization of SARS and COVID-19}

The 2002-2004 severe acute respiratory syndrome, or SARS, outbreak, nicknamed "the first global epidemic of the twenty-first century" (Connor 2003), was a modern Sinophobic racialization of infectious disease. In November of 2002, the first signs of what would later lead to the epidemic were reported in Guangdong, China. In February of 2003, the Chinese government, unable to keep the proliferation of the disease a secret, informed the World Health Organization and, in effect, the international medical community ("Severe Acute Respiratory Syndrome" 2003). While scientific agencies and governments frantically sought to understand the disease and identify ways to combat it, trepidation ran rampant around the world. After all, fear of SARS was fear of a disease that remained biologically unexplained yet had proven fatal (Das 2001). As the global media dramatized SARS through their stories, the stigmatization of potential SARS victims and carriers ensued (Person et al. 2004, 358). In particular, Asian American communities were among the hardest hit as they were imagined to possess heightened potential for SARS pathogenicity (358). For instance, according to Laura Eichelberger (2007), New York City's Chinatown 
did not have a single reported SARS case, yet it was identified as a site of "contagion and risk" by the general public and subsequently recorded a tremendous drop in business and tourism (1284-85). Here, it is critical to understand that the 21st-century promulgation of these anti-Asian sentiments did not rely solely on in-person sights and experiences (as was typical of the classical period) but instead were able to readily reach larger, otherwise uninvolved, audiences and shape public opinion through mass media (Happer and Philo 2013).

Nearly two decades after SARS, the ongoing (as of this writing) COVID-19 pandemic has taken the world by storm in a global disease outbreak of threatening proportions in terms of both transmission rate and scope. On 31 December 2019, the government of the Chinese city of Wuhan confirmed the emergence of several cases of pneumonia of unknown cause. By 11 January, the Chinese media reported the first known death of a new coronavirus disease that would later be declared a global health emergency by the World Health Organization on 30 January. In February, the disease would formally be named coronavirus disease 2019 or COVID-19. Rapidly spreading around the world in the matter of weeks, the U.S. reported its first death on 29 February and declared a national emergency on 13 March. By early September, the confirmed number of global coronavirus cases (across at least 177 countries) neared fifteen million, and the death toll surpassed 600,000 in the absence of sufficient infection control measures and an effective vaccine (Taylor 2020).

Like SARS, COVID-19 has proven to be yet another Sinophobic racialization of disease. As the pandemic spread, anti-Chinese and (more broadly) anti-Asian sentiments and fears visibly metastasized across the internet. While the same occurred during SARS, this spread was understandably more rapid for COVID-19 because of newer and more widely used infomedia ecosystems marked by social media (Depoux et al. 2020). While the popular social media site Twitter enabled an anti-China political narrative through a surge in hashtags such as \#BlameChina, \#ChinaLiedPeopleDied, and \#ChinaVirus, other websites outlined anti-hate speech policies that attempted, but in many cases failed, to restrict Sinophobic sentiments. On websites that entirely lacked such policies, like 4chan, a popular anonymous language imageboard website, clearly hostile anti-Asian sentiments proliferated more aggressively (Zannettou et al. 2020; Schild et al. 2020). Traditional racial slurs, as well as new terms such as "kungflu" that associated COVID-19 with ethic and national identity, spiked in usage and racialized the ongoing pandemic. Examples of antiAsian comments included "Go eat a bat, Chang!" and "THIS IS BIOTERRORISM NUKE CHINA NOW." While it is unclear how exactly online anti-Asian attitudes translate into actual individual responses, normalization of xenophobic rhetoric, online or in-person, is known to have real-life implications, especially when these sentiments reinforce pre-existing historical tropes that associate certain racial/ethnic groups with diseases (Timberg and Chiu 2020).

Perhaps not coincidentally, the proliferation of these sentiments online was simultaneously coupled with an acute spike in real-life incidents targeting Asian Americans across at least thirty-six states. Several websites documented anti-Asian incidents, such as a hate crimes tracker by the Anti-Defamation League that has published a significant number of reports online since January 2020 ("Reports of Anti-Asian Assaults" 2020). A similar website titled, "Stop APPI Hate," further documented more than eleven hundred bias incidents, which included verbal attacks, shunning, violence, and boycotting of Asian-owned businesses (Timberg and Chiu 2020). In particular, the researcher behind "Stop APPI Hate" found that Asian Americans wearing face masks were at increased risk of discrimination. I will explore this phenomenon further in my investigation of the 
face mask's emergent symbolism in American society, as well as its key role in a newly emergent imagination of Chinese culture.

Prior to this investigation, however, it is interesting to note first what other modern scholars have previously identified as the prevailing imaginations of the Chinese in the contemporary period. While the disease-related Sinophobic discourses of the contemporary period are similarly diverse and multi-faceted like those of the classical period, scholars have identified two particularly pervasive and thereby notable imaginations regarding Chinese spaces and bodies. Moreover, although these imaginations were identified prior to COVID-19, it is important to note that they persist in the ongoing pandemic, suggesting a continuity of discourse across the contemporary period.

The first imagination of Chinese space is an exceptionalization of the Chinese wet market as a focal point where pragmatically novel diseases emerge. As noted earlier in the introduction of this work, Lynteris (2018b, 44-45) duly contrasts this modern exceptionalization with the classical imagination of wet markets as spaces of decay where archaic diseases (like bubonic plague and smallpox) reawakened. In the contemporary period, the imagined coexistence of animals and humans in cramped, unsanitary conditions in wet markets are seen through a scientific lens as a catalyst of menacing and/or unprecedented disease emergence. Rapid mutations enable the birth of potent viruses that are carried by animal vectors before jumping the species barrier and occasionally infecting human hosts. For both SARS and COVID-19, scientific reports, some of which have been debunked but nonetheless received by the public (Letzter 2020), have framed the Chinese wet market as a "pandemic ground zero" (Lynteris 2016). Thus, by extension, imagining wet markets as the (repeated) sources of these diseases frames them, and Chinese spaces in general, as breeding grounds for threatening infectious diseases of calamitous proportions.

The second imagination of Chinese bodies is the association of the Chinese with "superspreaders," those individuals with extraordinary ability to quickly spread disease. Supposedly, if a "typical" person is expected to infect four others, superspreaders can contaminate at least eight (Shen et al. 2004). The portrayal and promulgation of this imagination is largely rooted in the media. Priscilla Wald (2008) has demonstrated that the SARS narrative relied heavily on the symbolic figure of the superspreader, which effectively functioned as an explanation for modern epidemiology's failure to rapidly make sense of the virus' uncontrolled spread. During the SARS outbreak's peak, the New York Times, referring to the infected Chinese, noted that these "people are hyperinfective, spewing germs out like teakettles, while others simmer quietly like stew pots" (McNeil and Altman 2003). In turn, Lynteris (2018b) has stressed the significance of the superspreader in forging an epidemic imaginary that pathologized the "Chinese body" through what he calls a "mythic impact," where this body was framed as an extraordinarily contagious human type (46). Similar to SARS, the term "superspreader" (and thus its symbolic meanings) also proliferated online across newspapers headlines and various social media platforms during the COVID-19 pandemic at perhaps an even broader scale due to the aforementioned increased reach of infomedia ecosystems. Emma Cave (2020) criticizes the term's vague definition and usage in mainstream social media outside scientific circles and argues that such factors detract from its supposedly scientific nature by alluding to moral blame. While it is unlikely that the term will be avoided altogether given its widespread use in current scientific literature, intentional usage of "superspreading" and "superspreading events" over "superspreader" could potentially de-stigmatize the term. Better yet, Cave suggests that developing a clearer taxonomy and scientific definition of superspreading could counteract inappropriate nonscientific adoption. As it is, however, it is clear that epidemiologists must tread carefully in 
using terminology like "superspreader" especially when working with potentially flawed data to prevent lay mischaracterizations and further racialization of Chinese bodies.

Altogether, having acknowledged pre-existing scholarship on contemporary imaginations surrounding the Chinese and infectious disease, the repeated Sinophobic framing and discrimination of the COVID-19 pandemic to that of the past warrants a re-examination of the contemporary epidemic imaginary. In line with the genealogical premise established earlier in this work, I will demonstrate in the next section that, in spite of the apparent continuity of anti-Chinese discrimination across classical and contemporary eras, the Sinophobic attitudes of the contemporary period are predicated on inherently novel fears of the Chinese founded on their apparent embrace, rather than rejection, of scientific modernity.

\section{The contemporary imagination of the Chinese response to infectious disease}

In order to demonstrate this shift away from cultural rejection of modernity towards embrace, I will rely on a relatively unaddressed, yet immensely pervasive imagination of the Chinese that intrinsically characterizes their response to disease in the contemporary period: the "masked Chinese."

It was the 2002-2004 SARS epidemic that first gave rise to this novel imagination. As the highly infectious airborne disease spread quickly to urban centers around the world, Judy Yuen-man Siu (2016) notes that SARS facilitated an extraordinary transformation of China, where face masks became widely used throughout the entire country for the first time. The heavily impacted city of Hong Kong, in particular, saw a notably rapid mass adoption of face masks (reportedly upwards of ninety percent of all residents) as personal antiviral protection (Lau et al. 2004). Given the Chinese and broader Asian understanding of the face mask's role in self-protection and protection of the vulnerable, the face mask became a near ubiquitous and thereby highly visible symbol of an individual and collective cultural determination to achieve disease control (Syed et al. 2003, 856). In spite of their successful extensive adoption in Asia, a feat that would persist through COVID-19 as well, these very same face masks were simultaneously stigmatized in America.

During the SARS outbreak and the later COVID-19 pandemic, the Chinese became associated with face masks and, by extension, the two infectious diseases. Clare Ching Jen (2008) points out that the face mask was the "main visual symbol of SARS discourse" and was often portrayed by mass media in conjunction with Chinese (i.e. Chinese/Asianlooking) faces (134). For instance, major newspapers and broadcasters, such as the New York Times and $A B C$ News constantly promulgated photos of masked Asian figures (Bradsher and Eckholm 2003; "China SARS" 2003). COVID-19 proved no better as popular media outlets, again, established the Chinese/Asians to be the face of the crisis through photography that often framed them wandering through dreary urban dystopias adorned by face masks (Burton 2020). Indeed, few images better captured the ensuing Chinese-disease association than those of the widely recognized, albeit masked, face of Mao Zedong on the 26 April 2003 SARS edition cover of The Economist, as well as the similarly masked and well-known face of Chinese President Xi Jinping on the 17 February 2020 COVID-19 edition cover of TIME magazine (Economist 2003; Campbell 2020). Beyond simply racializing these infectious diseases, this repetitive imagery of the masked Chinese also enabled further pathologization of Chinese bodies. According to Susan Sontag's (1990) notion of "consciousness of risk," the repeated visualizations of a particular group in disease 
coverage can create perceptions of those groups as possessing increased risk and potential for infection. As such, the (often masked) Chinese were framed as inherently more susceptible to these diseases and more likely to spread them. It has been further theorized that these visualizations are able to subtly enter into the consciousnesses of their audiences and ingrain and/or reinforce prior Sinophobic prejudices (Wallis and Nerlich 2005; Joffe and Haarhoff 2002).

In addition to facilitating disease racialization and Sinophobic pathologization, the visual technoscientific object of the face mask itself aroused further fear through a striking technological dichotomy. This dichotomy, first investigated by Clare Ching Jen (2013) in her analysis of the masked Asian/American woman in SARS discourse, was of dueling technophilia and technophobia. On one hand, it represented technophilic Asian co-existence with technology as face masks became part of daily attire and even commodified as voguish fashion in areas particularly affected by SARS (118). For instance, Jen writes that these masks, which were often adorned by colorful designs and designer logos, stylishly decorated everyday residents on the streets of Hong Kong, a sight that would similarly hold true for COVID-19 (Ward 2020). Simultaneously, this very harmony between technology and humans was viewed through a technophobic lens as a frightening image. While the face mask, in some sense, suggested public health safety as a piece of personal protective equipment, it was simultaneously an acknowledgment and perhaps resignation to the realization of one's susceptibility to disease (119).

Given this dual emphasis on the face mask's technological symbolism, it is interesting to consider further the broader implications of this imagination on the Western stigmatization of Chinese communities that comprehensively adopted face masks. In the Los Angeles Times article "Fear Goes Global," Mitchell Koss, a reporter headed to Hong Kong to investigate SARS prior to the Chinese government's acknowledgement of the outbreak, described the scene of masked Chinese:

It was beginning to feel as if we were in a low-budget science fiction movie. There were minimal special effects - cheap surgical masks - and a monster that you couldn't see: the virus. Even without a menacing soundtrack, it was hard to escape the sense that something was out there. Lurking. Waiting to attack. (Koss 2003).

Through this eerie science fiction-like imagery, Koss not only demonizes the SARS contagion but also inadvertently frames the masked faces, themselves, as early signs of a daunting technological future emanating from China (Jen 2008, 140-142). In portraying masks as a new norm in his account, the boundary between what is human and what is technology has been blurred by the haunting, incongruous, and dehumanizing image of mask-wearing Chinese. Even amidst COVID-19, in Western societies that have resisted adopting the face mask en masse as a collective culture, the image of a "masked" society like China continues to be perceived as a somewhat alien, alarming, and hopefully shortlived sight. This sentiment has recently been made clear by American leaders like President Donald Trump, who (when referring to America's own "masked" transformation) in March of 2020 expressed, "We want our country back. We're not going to be wearing masks forever" (Friedman 2020). Indeed, Koss was correct two-fold for both SARS and COVID-19 about an imminent, and perhaps terrifying, technological future characterized by masked faces, and, by association, the Chinese were apparent harbingers of this impending doom.

The fundamental basis behind this fear of a technological future is further revealed upon a closer examination into what the mass adoption of face masks and subsequent "masked Chinese" image not only foreshadow but also directly represent, specifically in terms of Chinese disease response and culture. Christos Lynteris (2018a) has traced the advent of anti-epidemic 
personal protection equipment (i.e. face masks) since their invention in the 1910-11 Manchurian plague outbreak. As face masks are understood as technoscientific objects that are intrinsically connected to identity, personhood, and even transformation, they embody not only a means of halting infection based on bacteriological principles, but also of a categorical transformation of their wearers into "reasoned subjects of hygienic modernity" (Lynteris 2018a, 443; Rogaski 2004). In other words, Lynteris (2018a) explains that the face mask is a "mask of reason" representing a transformation from "unreason" to "reason" of both individuals and the cultures that embrace it and its foundational scientific bases (451). While it is important to acknowledge that the anti-epidemic face mask was invented well within the range of the classical period, the imagination surrounding the "masked Chinese" was irrelevant to the public consciousness at the time and thus insignificant prior to the face mask's mass adoption during the contemporary period. In regards to the contemporary period, however, the symbolic configuration of the face mask as a transformative agent of its wearer can be extrapolated to view the "masked Chinese" as a frightening imagination that asserts intimidating, newly emergent Chinese cultural embrace of modernity and, in the words of Lynteris, "indisputable, photogenic, proof of Chinese scientific sovereignty" (452). While imagination of the "masked Chinese" may thus serve as strong evidence of a deviation in the public understanding of Chinese disease response, as well as Chinese culture overall, from its classical rejection of modernity, I further offer this imagination as a starting point towards greater sensitivity in identifying broader shifts in the overarching epidemic narrative.

Diametrically opposed to the classical epidemic narratives predicating upon a Chinese cultural repudiation of modernity, contemporary narratives of blame have instead emphasized an unrestrained and alarming exploitation of this very modernity (i.e. a magnitude above a mere "embrace"). One major example of this is a recent widespread narrative that framed COVID19 as a Chinese bioweapon. In January 2020, the Washington Times published an article suggesting that the SARS-CoV-2 coronavirus (responsible for COVID-19) may have originated in a Wuhan lab associated with China's biowarfare program (Gertz 2020). BBC News soon reported that hundreds of accounts cited this article, in addition to another one that made similar claims, to promulgate a "COVID-19 bioweapon" theory to a potential audience of millions (BBC News 2020a). While newspapers like the Washington Post attempted later to challenge this fringe theory, citing widespread abandonment of bioweapon programs and the absence of evidence suggesting that the coronavirus had been genetically engineered (Washington Post 2020), an analysis of the widely used social media platform Twitter showed the presence of online "troll bots" that had already flooded the platform with unfounded claims of intentional Chinese development of the coronavirus (Benson 2020). As of this writing, however, the official origins of the coronavirus remain uncertain, and no scientific evidence currently suggests that the virus is a bioweapon ("Is COVID-19 a Biological Weapon?" 2020). Finally, while I do not claim that this singular epidemic narrative is representative of the entirety of contemporary discourse, its very emergence in the first place marks a significant divergence from the narratives of the classical period, a discrepancy that must be taken into account by scholars moving forward.

\section{Conclusion}

Understanding the Yellow Peril discourses of the past and present requires the positioning of our analytical gaze beyond the imagined mode of disease generation to encompass the epidemic imaginary surrounding population and cultural disease responses. In this comparative 
analysis of the imagined Chinese response to disease during Sinophobic epidemics across the classical and contemporary periods, a fundamental shift in the imaginations and epidemic narratives that inextricably identified the Chinese and their culture with infectious diseases has become apparent.

Whereas the classical period of the late 19th- and early 20th-century pathologized the Chinese through imaginations of a degenerate, outdated culture stubbornly predicated on traditional beliefs and categorically rejecting scientific modernity, the contemporary 21 st-century imagination of the "masked Chinese" has reframed this culture as a champion, in terms of faith and mastery, of this very modernity. Newly emergent bioweapon/bioterrorism fringe theories amidst COVID-19 discourse provide further evidence of a reversal of the Chinesedisease paradigm that now perceives Chinese culture as a novel threat of not only scientific embrace but also technoscientific exploitation.

While the reasons for this reversal are undoubtedly complex in historical and political origin, the Western perception of China's relatively recent rise in status from the declining society of the late Qing dynasty to a new global superpower has likely played a central role. Through the COVID-19 pandemic alone, the nation has demonstrated its newfound influence in its domestic and international public health responses. Upon the disease's emergence in January 2020, the world witnessed China's expeditious control of infection through a comprehensive lockdown of Wuhan, the well-documented construction of hospital testing facilities at a remarkable rate (BBC News 2020b) and the mass importation of an estimated fifty-six million respirators and surgical masks within just a week of the initial lockdown (Yang 2020). Moreover, the essential nature of protective medical gear has ushered in a new era of "mask diplomacy," in which China's overwhelming control over global surgical mask output/allocation has forced pleas from desperate nations for increased production (Brasher and Alderman 2020). China's influence over global public health may have become more pronounced in recent months, but it is reflective of a broader understanding of China as a novel source of wealth, power, productivity, and novelty. Lynteris $(2018 \mathrm{~b}, 49)$ has proposed that modern China, in many senses, represents the "realization of the West's own fantasy of unrestrained capitalist production and exploitation." Such could similarly be the basis for contemporary fears of a Chinese abuse of modernity.

Understanding the forces that have and continue to drive this reversal of epidemic narrative is a necessary step in the quest to prevent future Sinophobic discourses and disease racialization, but it is perhaps equally pertinent that references back to a bygone era of Yellow Peril are applied with the utmost care in analyzing the Sinophobic discourses of today. Scholars and leaders alike must remain vigilant not to disregard these fundamental discontinuities for the sake of mere political convenience. The pre-pandemic conclusions of Lynteris (2018b) will hold true (perhaps even more so) in a post-pandemic world, and as such, I echo and adapt them here amidst COVID-19. Our understandings of Chinese disease associations must strive to be increasingly nuanced and precise if scholars, epidemiologists, policymakers, community leaders, and the mass media are to help mitigate future racialization of epidemics and infectious disease. To achieve this, we must not address modern Sinophobia solely as the remnant of an archaic past, but instead as an independent phenomenon driven by the political, economic, technological, and sociocultural dynamics of a new era.

\section{References}

BBC News. 2020a. "China Coronavirus: Misinformation Spreads Online,” January 30. https://www.bbc. com/news/blogs-trending-51271037. 
BBC News. 2020b. "Coronavirus: The Hospital Built in a Matter of Days," February 2. https://www.bbc. com/news/in-pictures-51280586.

Benson, Thor. 2020. "Bots Are Waging a Coronavirus Disinformation Campaign on Social Media." Inverse. Accessed September 1, 2020. https://www.inverse.com/innovation/bots-are-spreading-lies-about-thecoronavirus-on-social-media.

Bradsher, Keith, and Erik Eckholm. 2003. "SARS Spreads in Taiwan; W.H.O. Plans Trip There.” New York Times, May 3. International edition. https://www.nytimes.com/2003/05/03/world/the-sars-epidemicthe-implications-sars-spreads-in-taiwan-who-plans-trip-there.html.

Bradsher, Keith, and Liz Alderman. 2020. "The World Needs Masks. China Makes Them, but Has Been Hoarding Them." New York Times, March 13. https://www.nytimes.com/2020/03/13/business/masks -china-coronavirus.html.

Burton, Nylah. 2020. "Why Asians in Masks Should Not Be the 'Face' of the Coronavirus." Vox, March 6. https://www.vox.com/identities/2020/3/6/21166625/coronavirus-photos-racism.

Campbell, Charlie. 2020. "China's Test.” TIME, February 17. https://time.com/magazine/us/5778979/febru ary-17th-2020-vol-195-no-6-u-s/.

Cave, Emma. 2020. "COVID-19 Super-Spreaders: Definitional Quandaries and Implications." Asian Bioethics Review 12: 235-242. https://doi.org/10.1007/s41649-020-00118-2.

"China SARS." 2003. ABC News. American Broadcasting Company. 369695. AP Archive.

Connor, Steve. 2003. "The First Global Epidemic of the 21st Century." Independent, April 25. https://www. independent.co.uk/news/science/the-first-global-epidemic-of-the-21st-century-116575.html.

Das, Veena. 2001. "Stigma, Contagion, Defect: Issues in the Anthropology of Public Health.” In Stigma and Global Health: Developing a Research Agenda. Bethesda, Maryland: National Institutes of Health. https://web.archive.org/web/20130318041954/http://www.stigmaconference.nih.gov/FinalDasPaper. htm.

Depoux, Anneliese, Sam Martin, Emilie Karafillakis, Raman Preet, Annelies Wilder-Smith, and Heidi Larson. 2020. "The Pandemic of Social Media Panic Travels Faster than the COVID-19 Outbreak." Journal of Travel Medicine 27 (3). https://doi.org/10.1093/jtm/taaa031.

Economist. 2003. "The SARS Virus.” April 26. https://www.economist.com/weeklyedition/2003-04-26.

Eichelberger, Laura. 2007. "SARS and New York's Chinatown: The Politics of Risk and Blame during an Epidemic of Fear." Social Science \& Medicine 65 (6): 1284-95. https://doi.org/10.1016/j.socsc imed.2007.04.022.

Fong, T. P. 2002. The Contemporary Asian American Experience: Beyond the Model Minority. 2nd edition. Upper Saddle River, NJ: Prentice Hall.

Foucault, Michel. 1977. "Nietzsche, Genealogy, History." In Language, Counter-Memory, Practice: Selected Essays and Interviews, edited by D. F. Bouchard, 139-65. Ithaca: Cornell University Press.

Friedman, Uri. 2020. "Face Masks Are In." The Atlantic. April 2. https://www.theatlantic.com/politics/archi ve/2020/04/america-asia-face-mask-coronavirus/609283/.

Gertz, Bill. 2020. "Coronavirus may Have Originated in Lab Linked to China's Biowarfare Program." Washington Times, January 26. https://www.washingtontimes.com/news/2020/jan/26/coronavirus-linkto-china-biowarfare-program-possi/.

Happer, Catherine, and Greg Philo. 2013. "The Role of the Media in the Construction of Public Belief and Social Change." Journal of Social and Political Psychology 1 (1): 321-36. https://doi.org/10.5964/ jspp.v1i1.96.

Heinrich, Larissa N. 2008. The Afterlife of Images: Translating the Pathological Body between China and the West. Durham, NC: Duke University Press.

Hopkins, Donald R. 1983. Princes and Peasants: Smallpox in History. Chicago: University of Chicago Press.

"Is COVID-19 a Biological Weapon?" 2020. New Jersey COVID-19 Information Hub. March 11. https:// covid19.nj.gov/faqs/coronavirus-information/about-the-virus/is-covid-19-a-biological-weapon.

Jen, Clare Ching. 2008. "SARS Discourse Analysis: Technoscientific Race-Nation-Gender Formations in Public Health Discourse.” PhD, Graduate School of the University of Maryland.

----. 2013. "How to Survive Contagion, Disease, and Disaster: The 'Masked Asian/American Woman' as Low-Tech Specter of Emergency Preparedness." Feminist Formations 25 (2): 107-28.

Joffe, H., and G. Haarhoff. 2002. "Representations of Far-Flung Illnesses: The Case of Ebola in Britain." Social Science \& Medicine 54 (6): 955-69.

Kim, Grace S., and Tanvi N. Shah. 2020. "When Perceptions Are Fragile But Also Enduring: An Asian American Reflection on COVID-19.” Journal of Humanistic Psychology 60 (5): 604-10. https://doi. org/10.1177/0022167820937485.

Koss, Mitchell. 2003. "Fear Goes Global." LA Times, April 27. https://www.latimes.com/archives/la-xpm2003-apr-27-op-koss27-story.html. 
Lau, Joseph T.F., Hiyi Tsui, Mason Lau, and Xilin Yang. 2004. "SARS Transmission, Risk Factors, and Prevention in Hong Kong." Emerging Infectious Diseases 10 (4): 587-92. https://doi.org/10.3201/ eid1004.030628.

Lee, R. 1999. Orientals: Asian Americans in Popular Culture. Philadelphia: Temple University Press.

Lee, Rose Hum. 1960. The Chinese in the United States of America. Hong Kong: Hong Kong University Press.

Letzter, Rafi. 2020. “The Coronavirus Didn't Really Start at That Wuhan 'Wet Market.” Live Science, May 28. https://www.livescience.com/covid-19-did-not-start-at-wuhan-wet-market.html.

Lynteris, Christos. 2016. "The Prophetic Faculty of Epidemic Photography: Chinese Wet Markets and the Imagination of the Next Pandemic." Visual Anthropology 29 (2): 118-32. https://doi. org/10.1080/08949468.2016.1131484.

----. 2018a. "Plague Masks: The Visual Emergence of Anti-Epidemic Personal Protection Equipment." Medical Anthropology Journal 37 (6): 442-57. https://doi.org/10.1080/01459740.2017.1423072.

----. 2018b. "Yellow Peril Epidemics: The Political Ontology of Degeneration and Emergence." In Yellow Perils: China Narratives in the Contemporary World, edited by Franck Bille and Soren Urbansky, 34-53. Honolulu: University of Hawaii Press.

McClain, Charles. 1988. "Of Medicine, Race, and American Law: The Bubonic Plague Outbreak of 1900." Law \& Social Inquiry 13 (3): 447-513. https://doi.org/10.1111/j.1747-4469.1988.tb01126.x.

McNeil, D. G., and L. K. Altman. 2003. "How One Person Can Fuel an Epidemic." New York Times, April 15. http://www.nytimes.com/2003/04/15/science/how-one-person-can-fuel-an- epidemic. html.

Miller, Stuart Creighton. 1969. The Unwelcome Immigrant: The American Image of the Chinese, 17851882. Oakland, CA: University of California Press.

Okihiro, G. Y. 1994. Margins and Mainstreams: Asians in American History and Culture. Seattle: University of Washington Press.

Person, Bobbie, Francisco Sy, Kelly Holton, Barbara Govert, and Arthur Liang. 2004. "Fear and Stigma: The Epidemic within the SARS Outbreak." Emerging Infectious Diseases 10 (2). https://wwwnc .cdc.gov/eid/.

"Reports of Anti-Asian Assaults, Harassment and Hate Crimes Rise as Coronavirus Spreads." 2020. Anti-Defamation League. July 18. https://www.adl.org/blog/reports-of-anti-asian-assaults-haras sment-and-hate-crimes-rise-as-coronavirus-spreads.

Risse, Guenter B. 2012. Plague, Fear, and Politics in San Francisco's Chinatown. Baltimore, MD: John Hopkins University Press.

Rogaski, Ruth. 2004. Hygienic Modernity: Meanings of Health and Disease in Treaty-Port China. Asia: Local Studies / Global Themes. Oakland, CA: University of California Press.

San Francisco Call. 1900. "Chinatown Quarantined." March 8. California Digital Newspaper Collection.

San Francisco Chronicle. 1876. "Importing Disease.” May 20. ProQuest Historical Newspapers: San Francisco Chronicle. http://ezproxy.cul.columbia.edu/login?url=https://www-proquest-com.ezproxy.cul. columbia.edu/historical-newspapers/importing-disease/docview/357220042/se-2?accountid=10226.

"San Francisco Municipal Reports." 1887. University of California. HathiTrust. https://hdl.handl e.net/2027/uc1.32106013966095?urlappend=\%3Bseq $=429$.

Schild, Leonard, Chen Ling, Jeremy Blackburn, Gianluca Stringhini, Yang Zhang, and Savvas Zannettou. 2020. "'Go Eat a Bat, Chang!': An Early Look on the Emergence of Sinophobic Behavior on Web Communities in the Face of COVID-19." arXiv. http://arxiv.org/abs/2004.04046.

"Severe Acute Respiratory Syndrome (SARS) Multi-Country Outbreak - Update 6." 2003. World Health Organization. https://www.who.int/csr/don/2003_03_21/en/.

Shen, Zhuang, Fang Ning, Weigong Zhou, Xiong He, Changying Lin, Daniel P. Chin, Zhonghan Zhu, and Anne Schuchat. 2004. "Superspreading SARS Events, Beijing, 2003." Emerging Infectious Diseases 10 (2): 256-60.

Siu, Judy Yuen-man. 2016. "Qualitative Study on the Shifting Sociocultural Meanings of the Facemask in Hong Kong since the Severe Acute Respiratory Syndrome (SARS) Outbreak: Implications for Infection Control in the Post-SARS Era." Siu International Journal for Equity in Health 15 (73). https://doi.org/10.1186/s12939-016-0358-0.

Sontag, Susan. 1990. Illness as Metaphor: And, Aids and Its Metaphors. New York: Doubleday.

Syed, Q., W. Sopwith, M. Regan, and M. A. Bellis. 2003. "Behind the Mask. Journey through an Epidemic: Some Observations of Contrasting Public Health Responses to SARS." Journal of Epidemiology and Community Health 57 (11): 855-56.

Takaki, Ronald. 1998. Strangers from a Different Shore: A History of Asian Americans. Rev. Little, Brown and Company. 
Taylor, Derrick Bryson. 2020. “A Timeline of the Coronavirus Pandemic.” New York Times, August 6. https ://www.nytimes.com/article/coronavirus-timeline.html.

Tessler, Hannah, Meera Choi, and Grace Kao. 2020. "The Anxiety of Being Asian American: Hate Crimes and Negative Biases During the COVID-19 Pandemic." American Journal of Criminal Justice Volume 45: 636-46. https://doi.org/10.1007/s12103-020-09541-5.

Timberg, Craig, and Allyson Chiu. 2020. "As the Coronavirus Spreads, so does Online Racism Targeting Asians, New Research Shows." Washington Post, April 8. https://www.washingtonpost.com/techn ology/2020/04/08/coronavirus-spreads-so-does-online-racism-targeting-asians-new-research-shows/.

Trauner, Joan B. 1978. "Chinese as Medical Scapegoats, 1870-1905.” California History Magazine. http:// www.foundsf.org/index.php?title=Chinese_as_Medical_Scapegoats,_1870-1905.

Wald, Priscilla. 2008. Contagious: Cultures, Carriers, and the Outbreak Narrative. Durham: Duke University Press.

Wallis, Patrick, and Brigitte Nerlich. 2005. "Disease Metaphors in New Epidemics: The UK Media Framing of the 2003 SARS Epidemic.” Social Science \& Medicine 60 (11): 2629-39.

Ward, Alex. 2020. "How Masks Helped Hong Kong Control the Coronavirus." Vox. May 18. https://www. vox.com/2020/5/18/21262273/coronavirus-hong-kong-masks-deaths-new-york.

Washington Post. 2020. “China's Coronavirus Has No Links to Weapons Research, Experts Say,” January 29. https://www.washingtonpost.com/.

Yang, Si. 2020. "China, Home of COVID-19, Turns to 'Mask Diplomacy' to Burnish Image." Voice of America News. March 19. https://www.voanews.com/science-health/coronavirus-outbreak/china -home-covid-19-turns-mask-diplomacy-burnish-image.

Zannettou, Savvas, Jason Baumgartner, Joel Finkelstein, and Alex Goldenberg. n.d. "WEAPONIZED INFORMATION OUTBREAK: A Case Study on COVID-19, Bioweapon Myths, and the Asian Conspiracy Meme." The Network Contagion Research Institute. Accessed July 24, 2020. https://ncri.io/ reports/weaponized-information-outbreak-a-case-study-on-covid-19-bioweapon-myths-and-the-asian -conspiracy-meme/.

Publisher's Note Springer Nature remains neutral with regard to jurisdictional claims in published maps and institutional affiliations. 